\title{
Is $\mathrm{MeCP} 2$ a Gene Suppressor or Activator? Shikun $\mathrm{He}^{1 *}$ and Haike Guo MD² \\ ${ }^{1}$ Departments of pathology and ophthalmology, Keck School of Medicine of University of Southern California, Los Angeles, CA ${ }^{2}$ Henan Eye Hospital, Henan Eye Institute,Zhengzhou, and Guangzhou Eye Institute, Guangzhou, China
}

Methyl-CpG binding protein 2 (MeCP2) was first identified in 1992; The MeCP2 protein binds to DNA where it is methylated. Mutations in the MeCP2 gene lead to Rett syndrome. MeCP2 binds to methylated DNA and act as a transcriptional repressor [1]. One of critical function of MeCP2 in the modulation of gene expression is to alter chromatin structure [2]. Cataract is one of typical example of high expression of MeCP2 in gene promoters of alpha a crystalline and promote the formation of cataract [3].

More recent work demonstrated that $\mathrm{MeCP} 2$ also binds at actively transcribed genes and promotes activation of DNA-methylated genes, suggesting a role as a transcriptional activator [1].Through a large-scale mapping of MeCP2 binding sites in neurons, it was found that less than $6 \%$ of the MeCP2 binding sites are highly methylated, however, majority of $\mathrm{MeCP} 2$-bound promoters are related gene activation, suggestion that $\mathrm{MeCP} 2$ function as a gene activator [4]. So the key question remains to be answered, is $\mathrm{MeCP} 2$ just a transcriptional gene repressor? Or it is a multifunctional protein function as a gene activator?

MeCP2 has multiple posttranslational modification including phosphorylation, acetylation and ubiquityaltion. MeCP2 is ubiquitously expressed in the mammalian central nervous system and many other non-neuron cells. The expression of $\mathrm{MeCP} 2$ is low during early life but it increases progressively following neuron development. It is demonstrated that brain-derived neurotrophic factor (BDNF), insulinlike growth factor binding protein 3 (IGFBP3), the ubiquitin ligase UBE3A, $\gamma$-aminobutyric acid (GABA) receptor and the inhibitor of DNA binding (Id) proteins are regulated by $\mathrm{MeCP} 2 . \mathrm{MeCP} 2$ regulates gene in the ways gene- specific and genome-wide mechanism. MeCP2 has been shown to regulate a number of physiological and pathological conditions, such as development, cell signaling, cell proliferation and differentiation, tumorgenesis, and neuronal and degenerative diseases $[3,4]$. MeCP2 was recognized as a gene repressor in methylated promoters, due to the existing of a domain in the MeCP2 protein that play a role as transcriptional repression and the formation of gene suppression complex with Sin3A, HDAC and MeCP2. The other molecular involved in the transcriptionally silence collaborated with $\mathrm{MeCP} 2$ is HP1 [5].Loss of MeCP2 results in the up-regulation of many genes, knocking down MeCP2 by siRNA increases the expression of PPAR- $\$ and in MeCP2 knockout mice the PPAR-r expression is severe times higher compared to wide type mice. The removal of MeCP2 from $\mathrm{CpG}$ islands may result in the removal of gene repression and enable the binding of transcriptional activators to gene promoters. Indeed MeCP2 mediates certainly gene silence.

Besides suppress gene expression, $\mathrm{MeCP} 2$ also is a gene activator. It has been shown highly expressed MeCP2 is correlated to liver cell trans differentiated [6],cell loss polarization, increased calcium influx, cAMP- activation, neutrophophin signaling, and most importantly inflammation response [7]. Interestingly, Ping et al. found that MeCP2 is the upstream of VEGF and regulates VEGF expression in carcinoma cells [8]. Recent studies suggest MeCP2 also regulates wound healing process. In a rat liver fibrosis model, $\mathrm{MeCP} 2$ expression is associated predominately with myofibroblastic cells and is selectively expressed in fibrotic tissues [6]. Knock down MeCP2 by specific siRNA down regulates TGF $\beta$ expression and inhibits $S m a d 2 / 3$ activation and $\alpha$-SMA [3], fibronectin expression induced by TGF $\beta$. On the other hand, MeCP2 is also regulated by other factor such as CREB1; increased CREB1 expression in turn induces miRNA132 (a negative regulator of MeCP2) and result in decreased MeCP2. miRNA132 is found to be an important factor to repress MeCP2 transcription, therefore, miRNA132and most recently discovered miRNA483-5pcan be a regulatory molecular for $\mathrm{MeCP} 2$ as well [9]. it is known that phosphorylation of MeCP2 lead to dissociation of sin3, HADC and MeCP2 from a transcription repress to be a gene activator, specifically phosphorylation of MeCP2 on serine 80 or serine 421 is related to gene silencing or activation respectively $[10,11]$. Stimulation of neuronal activity is associated with the loss of phosphorylation at serine 80.In contrast, neuronal activity was accompanied by phosphorylation at serine 421 . Furthermore, knockin mice of phospho-MeCP2-80 or -421 show distinct consequences in vivo, where MeCP2-80 phosphorylation is associated with certain gene inhibition and MeCP2-421 phosphorylation is linked to gene activation $[12,13]$. More importantly, MeCP2-80 phosphorylation is relevant to apoptosis [14], suggesting that the phosphorylation of MeCP2-80 and that of MeCP2-421 play different roles in gene regulation. This may allow an individual MeCP2 molecule to act as either a transcriptional activator or a repressor, depending on its specific modifications. In the nervous system, MeCP2 phosphorylation activated by extracellular signals dynamically regulates gene expression. In particular, dendritic growth and spine maturation are also regulated by phosphorylation of $\mathrm{MeCP} 2$ at Ser 421[12]. In contrast, however, MeCP2-S80 phosphorylation inhibits a number of downstream genes that are essential for some neuronal functions $[12,13]$. Thus, phosphorylated MeCP2-421 may be permissive for changes in transcriptional regulation rather than for inhibition of gene activation $[12,15,16]$. Besides MeCP2 421 other amino acids residues such as s86, s274, T308 also enhances the expression of genes through $\mathrm{MeCP} 2$ phosphorylation [17].

$\mathrm{MeCP} 2$ plays numbers distinct roles in the regulation of gene expression: First, $\mathrm{MeCP} 2$ acts as a transcriptional repressor; Second, $\mathrm{MeCP} 2$ can also act as a gene activator in response to multiple stimulators. Third, as indicated by Chao et al MeCP2 is an important molecular which function like switch of Yin and Yang in cell homeostasis maintaining [10]. Forth the response of MeCP2 to stimulator can be positive or negative at different times [18]. Fifth transcription activities can be modulated by MeCP2-induced chromatin unfolding [19]. Taken together, depending on microenvironmentMeCP2 can function as a transcript repressor, also acts as gene expression activator.

${ }^{*}$ Corresponding author: Shikun $\mathrm{He}$, Departments of Pathology and Ophthalmology, Keck School of Medicine of University of Southern California, Los Angeles, CA, USA, Tel: (323) 442-1179; E-mail: SHe@doheny.org

Received January 16, 2014; Accepted January 18, 2014; Published January 24 2014

Citation: Shikun He, Haike Guo MD (2014) Is MeCP2 a Gene Suppressor or Activator? J Biomol Res Ther 3: e128. doi: 10.4172/2167-7956.1000e128

Copyright: (c) 2014 Shikun He, et al. This is an open-access article distributed under the terms of the Creative Commons Attribution License, which permits unrestricted use, distribution, and reproduction in any medium, provided the original author and source are credited. 


\section{References}

1. Sol Díaz de León-Guerrero, Gustavo Pedraza-Alva, Leonor Pérez-Martínez (2011) In sickness and in health: the role of methyl-CpG binding protein 2 in the central nervous system. Eur J Neurosci33: 1563-1574.

2. Baker SA, Chen L, Wilkins D, Yu P, Lichtarge O, et al. (2013) A newly characterized AT-hook domain in MeCP2 determines clinical course of Rett syndrome and related disorders. Cell 152: 984-996.

3. Peng Z, Yi L, Sun XH (2011) Zebularine suppresses TGF-beta-induced lens epithelial cell-myofibroblast transdifferentiation by inhibiting MeCP2. Mol Vis 17: $2717-2723$

4. Yasui DH, Xu H, Dunaway KW, Lasalle JM, Jin LW, et al. (2013) MeCP2 modulates gene expression pathways in astrocytes. Mol Autism 25 4: 3.

5. Maartje C, Brink, Luijsterburg, Corella S Casas-Delucchi, Roel van Driel, et al (2013) A Role for MeCP2 in Switching Gene Activity via Chromatin Unfolding and HP1y Displacement. Plos One 8: e69347.

6. Bian EB, Huang C, Wang H, Chen XX, Tao H, et al. (2013) The role of methylCpG binding protein 2 in liver fibrosis. Toxicology 309: 9-14

7. Miao C, Yang Y, He X, Li J (2013) New advances of DNA methylation and histone modifications in rheumatoid arthritis, with special emphasis on MeCP2. Cell Signal 25: 875-882.

8. Ping SY, Shen KH, Yu DS (2013) Epigenetic regulation of vascular endothelia growth factor a dynamic expression in transitional cell carcinoma. MolCarcinog 52: $568-579$.

9. Han K, Gennarino VA, Lee Y, Pang K, Hashimoto-Torii K, et al. (2013) Humanspecific regulation of MeCP2 levels in fetal brains bymicroRNA miR-483-5p. Genes Dev 27: 485-490.
10. Chao HT, Zoghbi HY (2009) The yin and yang of MeCP2 phosphorylation. ProcNatlAcad Sci U S A 106: 4577-4578.

11. Rutlin M, Nelson SB (2011) MECP2: phosphorylated locally, acting globally. Neuron 72: 3-5.

12. Cohen S, Gabel HW, Hemberg M, Hutchinson AN, Sadacca LA, et al. (2011) Genome-wide activity-dependent MECP2 phosphorylation regulates nervous system development and function. Neuron 72: 72-85.

13. Tao J, Hu K, Chang Q, et al. (2009) Phosphorylation of MeCP2 at Serine 80 regulates its chromatin association and neurological function. ProcNatlAcadSci U S A 106: 4882-4887.

14. Bracaglia G, Conca B, Bergo A, Rusconi L, Zhou Z, et al. (2009) Methyl-CpGbinding protein 2 is phosphorylated by homeodomain-interacting protein kinase 2 and contributes to apoptosis. EMBO Rep 10: 1327-1333.

15. Hutchinson AN, Deng JV, Cohen S, West AE (2012) Phosphorylation of MeCP2 at Ser421 contributes to chronic antidepressant action. J Neurosci 32: 1435514363.

16. Zhong X, Li H, Chang Q (2012) MeCP2 phosphorylation is required for modulating synaptic scaling through mGluR5 J Neurosci 32: 12841-12847.

17. Ebert DH, Gabel HW, Robinson ND, Kastan NR, Hu LS, et al. (2013) Activitydependent phosphorylation of MeCP2 threonine 308 regulates interaction with NCoR. Nature 499: 341-345.

18. Gonzales M, Adams S, Dunaway K, LaSalle J (2012) Phosphorylation of Distinct Sites in MeCP2 Modifies Cofactor Associations and the Dynamics of Transcriptional Regulation. Mol Cell Biol 32: 2894-2903.

19. Brink M, Piebes D, Marloes L, Luijsterburg d et al. (2013) A Role for MeCP2 in Switching Gene Activity via Chromatin Unfolding and HP1c Displacement. Plos One 8: 1-14. 